\title{
CINCA syndrome
}

INSERM

\section{Source}

INSERM. (1999). Orphanet: an online rare disease and orphan drug data base. CINCA

syndrome. ORPHA:1451

Chronic Infantile Neurological, Cutaneous, and Articular (CINCA) syndrome is characterised by skin rash, joint involvement, chronic meningitis with granulocytes and, in some cases, sensorineural hearing loss and ocular signs. 